\title{
A Naturalistic Approach of Human Enhancement Ethics
}

\author{
Jingtao Jiang \\ Research Centre of Medical Humanities, Zunyi Medical University, Zunyi, China
}

Email address:

jjt@zmu.edu.cn

\section{To cite this article:}

Jingtao Jiang. A Naturalistic Approach of Human Enhancement Ethics. Science, Technology \& Public Policy. Vol. 4, No. 2, 2020 , pp. 54-59. doi: $10.11648 /$ j.stpp.20200402.12

Received: May 18, 2020; Accepted: June 4, 2020; Published: June 15, 2020

\begin{abstract}
The debate between conservatism and progressivism of human enhancement ethics is essentially a debate between normative ethics and naturalistic ethics. Naturalistic ethics has a problem of "naturalistic fallacy", and normative ethics also has a problem of "normative paranoea". The former is a historical limitation of human cognitive ability which can be gradually solved with the development of science and technology, while the latter is a self-righteous positioning error of anthropocentrism. Therefore, normative ethics should give way to naturalistic ethics, and accordingly conservatism of human enhancement ethics should give way to progressivism. A naturalistic research approach is needed for human enhancement ethics. This naturalistic approach regards man as a living system that realizes its pursuit of balance through survival and development. Freedom is the pursuit of the balanced state of the living system, while survival and development are the process of the realizing of this pursuit. Equality is the fact that living systems are identical to other living systems and thus have equal influence in the higher systems of which they are composed. Democracy is a high-level system composed of living systems in which the dominant power is in the hands of most subsystems rather than a few. This as a whole constitutes a kind of naturalistic or systematic axiology.
\end{abstract}

Keywords: Human Enhancement Ethics, Normative Ethics, Naturalistic Ethics, System Axiology

\section{Introduction}

With the development of science and technology, some disciplines such as physics and chemistry enter a bottleneck and develop slowly, meanwhile the life science enters a explosion period and develops rapidly. People welcome the latest achievements of the development of life science, but the application of these achievements is strongly restricted by traditional ethical concepts and theories, which causes a lot of controversies. All of these controversies mainly focus on the ethical details arising from the application of life science and technology, while lack the deep axiological and philosophical thinking behind them. However, we should all realize that human enhancement is a profound great social revolution, and it is certainly not enough to just confine the analysis to the level of applied ethics. What we need now is a kind of axiological, philosophical level of thinking.

In view of this, this paper firstly sorts out the main contents of conservatism and progressivism of human enhancement ethics. Secondly, it points out that the nature of conservatism is normative ethics and the nature of progressivism is naturalistic ethics, and then advocates a progressive-naturalistic path of human enhancement ethics. Finally, this paper points out that this kind of progressive-naturalistic ethics is not anthropocentrism nor ecocentrism but living-system-centrism in between.

\section{Debate Between Conservatism and Progressivism of Human Enhancement Ethics}

The research of human enhancement ethics is still in the early stage of vigorous development, and various ethical viewpoints are springing up like bamboo shoots after a spring shower. Various scholars put forward their own unique opinions from different angles, and all these different angles of opinions mainly can be summed up into two camps of conservatism and progressivism. At the heart of the debate between these two camps is a disagreement over the challenges that human enhancement poses to the ideas of humanity and to the structure of society.

On Humanity 
Most conservatives believe that human nature is a series of fixed normative attributes that can not be changed, while human enhancement is to break these inherent attributes and bring a series of unpredictable consequences so should be forbidden. (a) Holiness argument. Human is an extraordinary being, given by god or nature, to be appreciated and feared and should never be disgraced. "The concern of playing God is rooted in the beliefs that no one has the power to create humans except God. Any attempts to do so or to modify human nature will cause harm" [1]. (b) Virtue-loss argument. The change of inherent human nature will lead to the loss of a series of original virtues."If the genetic revolution erodes our appreciation for the gifted character of human powers and achievements, it will transform three key features of our moral landscape - humility, responsibility, and solidarity" [2]. (c) Category argument. The category of human nature has a fixed scope, people can only pursue perfection within it and should never go beyond it, because the perfection outside the scope is non-human things and is meaningless to people. "removing human limits from sports is tantamount to removing the framework that gives it sense and meaning" [3].

Most progressives believe that human beings are not perfect actually, but in a dynamic process of pursuit of perfection, which is the true nature of human. (a) Defect argument. There are so many flaws in human nature that everyone wants to overcome them. "We envision the possibility of broadening human potential by overcoming aging, cognitive shortcomings, involuntary suffering, and our confinement to planet Earth" [4]. (b) Perfection argument. Everyone deep in their hearts has an internal motivation to accumulate progress to step into a higher level. "For transhumanists, as a species humans have always struggled to expand their capacities in ways that humans before them were not able to, and emerging biotechnologies, be they intended for therapeutic or enhancement purposes, are the most recent expression and onstrument of this essentially human drive tword self-improvement" [5]. (c) construction argument. Human nature is not fixed, innate or eternal, but influenced and constructed by different cultures. "Of all the implications that first-wave cybernetics conveyed, perhaps none was more disturbing and potentially revolutionary than the idea that the boundaries of the human subject are constructed rather than given" [6].

On Society

Most conservatives believe that liberty, equality and democracy are natural rights that can never be questioned or changed. However, the implement of human enhancement technology will break these believes and bring about a series of unpredictable consequences, and so should be forbidden. (a) liberty argument. Liberty implies that we should never be controlled by other things, but the gene editing baby technology makes our birth itself controlled by parents or others."It is worth noting, however, that liberal thinkers from Locke to Kant to Habermas accept the idea that freedom depends on an origin or standpoint that exceeds our control" [2]. (b) Equality argument. Equality is that people should be exactly equal to each other or at least equal in political rights, but human enhancement is running in the opposite direction. "The more forms of enhancement become available, the bigger the ability divide will become" [7]. (c) Democracy argument. Democracy is that the power resides in the hands of the majority of ordinary people while weakening the influence of a few elites at the top, but the application of human enhancement technology will instead strength the power of the upper class. Kass holds that implementation of human enhancement technologies would likely lead to the "naturalizing" of social hierarchies or place new means of control in the hands of totalitarian regimes [8].

Progressives generally believe that human enhancement can better promote the realization of liberty, equality and democracy. (a) liberty argument. It is the diversified free choices under different circumstances that the liberty in real life is. "since values differ and uncertainties in knowledge and intelligence make people come to opposing conclusions about the best way of acting even when their goals are exactly the same, there is a need for freedom to enable different approaches to be tested, compared and pursued" [9]. (b) Equality argument. Equality in real life can only be a relative equality under certain conditions. Ronald Bailey thinks that liberalism is founded not on the proposition of effective equality of human beings, or de facto equality, but on the assertion of an equality in political rights and before the law, or de jure equality [10]. (c) Democracy argument. Democracy is not a slogan but a real, tangible increase in the power of ordinary people. The implement of human enhancement technology to ordinary people not just the privileged few can truly advance the realization of democracy, which depends on a good policy making. "we also need strong social democracies to ensure all citizens have access to these options, not just the affluent" [11].

\section{Debate Between Normativism and Naturalism of Human Enhancement Ethics}

\section{Conservatism and Normativism}

The holiness argument, virtue-loss argument and category argument of conservatism all emphasize and maintain a series of inherent attributes of human nature, and this inherent attributes actually are derived from a subjective "convention", a "ought" and a "norm". The Holiness argument holds that human nature is sacred and inviolable, and tries to construct various rituals and rules to defend it. While in the eyes of animals, these rituals and rules are merely mincing human games and human beings maybe just some kind of meat to eat. The virtue-loss argument holds that human nature is beautiful and should be cherished and spread in out society. While in the eyes of aliens, these beautiful virtues are merely subjective human feelings under unique human cultural backgrounds, and maybe the humility is cowardice, responsibility is stubbornness, and unity is closure in their culture. The category argument holds that human nature has standard prototypes that we should all move towards. While 
in the eyes of different academic circles, these standard prototypes are merely subjective intuitions of a few scholars in a few circles, and other scholars in other circles may have different intuitions. In conclusion, the core point of the human nature argument of conservatism is to insist on a normative "ought" or subjective "convention".

The liberty argument, equality argument and democracy argument of conservatism all emphasize and maintain a kind of abstract thinking of these related concepts, and this abstract thinking is actually derived from a subjective "ideal", a "ought", and a "norm". The Liberty argument holds that people should not be influenced or determined by others, but just as babies' looks are largely determined by their parents and children's personalities are largely determined by their environments, everything in the world is influenced by each other. The equality argument holds that people should be exactly equal to each other or at least equal in political rights, but just as the "ability divide" exists everywhere and social resources distributed according to the power, no two individuals are alike and there is always a difference in their power. The democracy argument holds that the minority should be subordinate to the majority on the basis of complete equality, but just as social hierarchy exists everywhere and a dominate of a dictator is just the extreme form of a dominate of a few elites, it is often the few elites who actually decide the choices of the vast public. In conclusion, the core point of the social structure argument of conservatism is to insist on a normative "ought" or subjective "ideal".

\section{Progressivism and Naturalism}

The defect argument, perfection argument and construction argument of progressivism all emphasize and maintain a dynamic changing attributes of human nature, and this changing attributes actually are derived from an objective "generalization", a "is" and a "nature". The defect argument holds that people are constantly correcting their flaws and making progresses, which is an inevitable fact in real life because of the needs for survival, otherwise mistakes will accumulate and eventually overwhelm them. For example, hunger, isolation and aging will wear down the existence of people so we have to do our best to overcome them. The perfection argument holds that people are constantly striving for a better even perfect future, which is an inevitable fact in real life because of the needs for develop, otherwise they will become rigid and restricted, unable to cope with the changing environment and will be eliminated. For example, more and more old people have to learn to use computers to avoid being separated from the society. The construction argument holds that human nature is determined by social culture, which has been constantly proved as a fact by different historical stages and different civilizations, otherwise there would be only one human nature without the differences between slave societies and democratic societies, between east Asian and west European. In conclusion, the core point of the human nature argument of progressivism is to insist on a naturalistic "is" or objective "generalization".

The liberty argument, equality argument and democracy argument of progressivism all emphasize and maintain a kind of practical thinking of these related concepts, and this practical thinking is actually derived from an objective "observation", a "is" and a "nature". The liberty argument holds that freedom in real life is a relative choice limited by our own conditions and those around us, such as what we choose to eat at noon based on our own taste preferences and external food supply. The equality argument holds that equality in real life is a kind of relative equality within specific abstract rules, just as our current equality is only embodied in a few abstract rules, such as one person, one vote, legal provisions, wage distribution, etc., and it requires strict supervision, and it is still subject to the influence of numerous interest variables in real life. The democracy argument holds that true democracy is to enhance the power of the majority of ordinary people so that they would have the real power to make the decision. For example, democracy cannot exist in a slavery society and democracy in modern society is realized by the influence of the civil rights movement with the overall strength of the citizens exceeds that of the bigwigs. Therefor, the core point of the progressivism' $\mathrm{s}$ argument on society is to insist on the naturalistic "is" or "objective observation" about the concepts of liberty, equality and nationality.

Normativism and Naturalism

Conservatism holds that human nature is a set of fixed attributes derived from subjective conventions, while freedom, equality and democracy are abstract concepts derived from subjective ideals. Progressivism holds that human nature is a set of dynamic attributes derived from objective generalization, while freedom, equality and democracy are practical experiences derived from objective observation. Therefore, it can be said that conservatism holds a position of normative ethics, and progressivism holds a position of naturalistic ethics, so the debate between conservatism and progressivism essentially implies the debate between normativism and naturalism. The core of this debate is mainly the Moore's naturalistic fallacy. Moore believes that "good" is a kind of 'ought', "value" and ideal "norm", and there is no any 'is', "fact" and tangible "nature" in real life that can be perfectly corresponding to it and can only be displayed unilaterally (Similar to Plato's theory of the ideal, the idea is a perfect abstract form, real life objects are their "shadow" or "copy"), so ethics can only be normative and not naturalistic.

Let's begin by acknowledging that there is some truth to Moore's argument, because indeed although the development of modern cognitive science has given us a deeper understanding of the human mind, there are still some mind-specific phenomena such as qualia, intentionality and emergence, which make it impossible for us to fully explain them with physical objects. However, given the fact that human science and technology are slowly accumulating and progressing, we believe that this is simply a question of historical limitations that will be gradually revealed as science and technology develop. But because this is many years away, we should not be reluctant to bridge the gap between "what is" and "what ought", "fact" and "value", 
"nature" and "norms" now. We accept the naturalistic fallacy and admit that for a long time it was impossible to use nature to neutralize the unique status of norms because of the historical limitations of naturalism, but at the same time we should also point out that the normativism lacks empirical credibility and there is a "normative paranoea".

Most of the moral schools of normativism are a kind of axiomatic system, whose original concepts and basic axioms are set as self-evident and incontestable. According to these concepts and axioms, a set of complex theorems, laws can be logically deduced. For example, utilitarians take the concept of "happiness" as the original concept, and the proposition of "promoting the maximum happiness of the largest number of people" as the basic axiom, and then to derive various specific behavior norms on this basis. However, there are some problems of this kind of normativism. (a) The original concepts and basic axioms are mostly rooted in the presupposition of intuition, which itself lacks logical and empirical reliability. Even the unquestionable intuition that all human beings acknowledged, such as the sun going around the earth, may be wrong. (b) intuitions in utilitarian ethics are only popular among a small group of utilitarians, and even though they seem so wise and great, believers in deontology ethics, virtue ethics, etc., do not recognize it. That is to say there are many kinds of intuitions and there is no criteria to judge them. (c) No matter how rigorous, elaborate, or grand a system of axioms is, it must be combined with empirical practice, especially in the field of morality. We can do moral practice without the system of moral axioms, but we can't talk about the system of moral axioms without moral practice, because it's meaningless. Furthermore, the idea of moral concepts and moral propositions cannot even arise without the empirical basis of moral practice.

Therefore, our previous trust or worship of moral norms, as well as our innate and unconscious attribution of the concepts of morality, value and goodness to normative ethics, is a kind of "normative paranoea", is to follow the feeling, is to use the intuition of a few people to oppress and distort the inner nature of everyone else. There is a story in Chinese Qing dynasty literature about a woman who, after waking up from a nap to find a swinging door curtain, killed herself on suspicion that someone was watching her and had lost her virginity. We might even call this a "normative heresy," which uses a set of smug moral beliefs to influence and control people's behavior. Of course, there are some reasonable elements in the various schools of normative ethics, but their fundamental orientation is wrong, so their doctrines need to be refuted. Further more what we need now is a new Renaissance, not against religious oppression, but against moral heresy. We should base the moral standpoint on the foundation of natural humanity and establish a set of naturalistic value system.

\section{System Axiology from the Perspective of Naturalism}

The system axiology opposes the anthropocentric position of traditional normative ethics but does not absolutely reject it because of the historical limitations of naturalism in the scientific understanding of human mind. We prefer to set up some normative propositions on the basis of naturalism in a limited way, and these normative propositions are only valied within these limitations. Another thing we need to note is that this system axiology also opposes the ecocentric position of traditional ecological ethics, because being ecologically centered also means that a kind of gaia ethics if the gaia hypothesis is true, a kind of universe ethics if the universal consciousness hypothesis is true, they're all for the non-human good and meaningless to our human beings. The naturalistic axiology and ethics we advocate here must be rooted in the value and interests of people as living systems, which can be called system axiology and system ethics. Finally, this system axiology can be sorted out and further constructed from the clues of process philosophy, system philosophy and ecological ethics. Whitehead's process philosophy has consciously understood and interpreted the value phenomenon of living body from a systematic perspective [12]. The systems philosopher Laszlo had a clear discussion of the value phenomenon of man as a living system, but unfortunately it did not expand further [13]. When it comes to ecological ethicists, although they also study the value phenomenon of human being as a living system, they focus on the large ecological system in natural world, in which human being is just a small link [14]. Here we are going to further take the human living system as the center and study the value demand and value satisfaction of its survival and development.

The system axiology holds that any system with internal structure has value phenomenon. The internal value demand is the resultant force pointing to a specific target or direction caused by the unbalanced interaction between various structures within the system. The external value satisfaction is the effect of the external system on this resultant force. If the joint forces of internal value demand and external value satisfaction is zero, we can say that the system has reached a steady equilibrium. The living systems of people will show up the force of inner value demand when their physical and psychology structure are out of balance, and then will seek the force of external value satisfaction to restore balance. The internal value demand system and the external value satisfaction system such as a sexual organ and a masturbation stick themselves have nothing to do with moral. The internal resultant force and the external acting force such as the hunger for sex and the vibration of masturbation stick themselves have nothing to do withe moral too. The interaction of the internal resultant force and the external acting force such as the action to satisfy the hunger of sex with the vibration of a masturbation stick itself has nothing to do with moral too. It is only by increasing or decreasing the balance of the system that morality is concerned. Promoting balance is pleasing and good while breaking the balance is tiresome and evil. The essence of morality is the result that increasing or decreasing the balance of a living system by the interaction of internal resultant force and external action force [15]. 
The instinct of all systems is to move towards equilibrium, where the internal resultant force and external action force are both zero, and only the "smallest particle", the "stationary isolated system" and the "largest universe" are truly balanced according to their definition. The state of "smallest particle" requires that the living system return to the original and ignorant state of individual particles, "You're from dust and to dust you will return", so that there is no internal or external force. The state of the "stationary isolated system" requires that the internal resultant force of the living system balance with the external action force, and to maintain this equilibrium the system must remain internally stationary and externally isolated. "Happiness is frozen in this eternal moment", no internal physical and mental changes and no external interference, but this is obviously very fragile or even impossible. The state of "largest universe" requires the living system to continuously explore, integrate and even control the resources and mysteries of the whole universe, so as to eventually become an ultimate system that is self-centered and integrates the whole universe. This is mainly because the living system of human beings has infinite desires, but this desire can only be infinite approximation to the state of satisfaction and can not really achieve it. For humans, the realization of the "smallest particle" state is accompanied by abstinence, elimination, and death, and this obviously means the self-denial of the living system of human beings. In the realization conditions of the "stationary isolated system", the requirement of not being influenced by the outside world can be possibly achieved, but the requirement of not having metabolic changes in body and mind is impossible. Only the state of "largest universe" is consistent with the inner desires, emotions, curiosity and other pursuits of human nature, which is more easily accepted by people [16].

System axiology holds that the influence of a system is the freedom of the system. In a higher level system composed of multiple subsystems, the corresponding rights of each subsystem is determinant by the ration of contribution or influence to the higher level system. For the living system of human beings, freedom can be simply defined as the effect of internal will on external objects (this external objects refer to all objects outside the human consciousness including one' own body), and the greater the degree of influence the greater the degree of freedom. In a community composed of two people, the remaining part after the interaction of their respect influences is the resultant force of the community. The contributions or the influence ratios of the two people in the resultant force are their rights in the community. If their influence ratios are equal then the two people are equal, and if their influence ratios are not equal then the two people shall enjoy the corresponding rights according to their ratio [17].

\section{Human Enhancement Ethics from the Perspective of System Axiology}

System axiology holds that human is a biological system, just like any natural system, which is bound to develop and evolve towards the equilibrium state of "largest universe" on the basis of maintaining its own survival. The difference is that human beings can consciously and actively make efforts to pursue it. People can improve themselves through learning, exercise, exploration and other ways, but this will still be subject to the bottleneck of maximum capacity of the function of human organ. We can use human enhancement technology to expand the limitations of human organs, so as to liberate human beings and to reach a future of infinite possibilities. This would put the human enhancement enterprise on a solid foundation of natural laws, rather than just a vague appeal.

In the view of system axiology, liberty depends on the size of individual strength or influence. The greater the influence, the stronger its ability to resist interference and make choices. With the help of human enhancement technology, human beings can greatly improve their influence and realize unlimited liberation and freedom.

In the view of system axiology, equality is not a kind of natural right, but depends on the influence of the members in community. The greater the influence of a member is the higher the authority, ability, freedom or level of the member in the community is, and the lower the influence is the lower the level is. If the influences of different members are equal and then their levels in the community are equal. There is no universal equality between all men, but only the approximate equality between the members of the same class. It is not in accordance with the laws of nature to deliberately restrict the members of the higher class to the lower, or to elevate the members of the lower class to the higher, unless it's a natural flow when the influences of the members change. The equality most people believed now ignores factors such as ability, resources and opportunities mainly because these factors cannot be easily understood or controlled, just like the ideal bevel experiment in physics. The application of human enhancement technology can promote our understanding and controlling of these variables and finally achieve real equality.

In the view of system axiology, the key to democracy is that the majority public has the dominant influence and is at the top of society. If it is only the condition that "the majority of people control the dominant influence", we can completely follow the traditional normative idea of "stealing from the rich and giving to the poor", but this will obviously discourage people's enthusiasm and curb the development and progress of society. The democracy of system axiology requires not only the majority public to have the dominant influence, but also to turn them into elites at the top of society, so that they can lead rather than restrict the progress of society. This means exactly the aim of high level authority, ability, freedom, and influence of the ordinary people that pursued by human enhancement technology.

\section{Acknowledgements}

This thesis is supported by the Social Science Foundation of Guizhou Province, NO: 19GZYB61. 


\section{References}

[1] Isa, N. M., and M. F. H. S. Shuri, (2018). Ethical concerns about human genetic enhancement in the Malay science fiction novels. Science And Engineering Ethics 24 (1): 109-127.

[2] Sandel, M. J. (2007). The Case Against Perfection: Ethics in the Age of Genetic Engineering. Cambridge: The Belknap Press of Harvard University Press, 86, 94.

[3] Tolleneer, J., S. Sterckx, and P. Bonte, (2012). Athletic Enhancement, Human Nature and Ethics: Threats and Opportunities of Doping Technologies. New York: Springer, 196.

[4] Moor, M., et al. (2013). "Transhumanist declaration". In The Transhumanist Reader: Classical and Contemporary Essays on the Science, Technology, and Philosophy of the Human Future. eds. M. More and V. M. Natasha, 54-55. Oxford, United Kingdom: Wiley-Blackwell.

[5] Sharon, T. (2014). Human Nature in an Age of Biotechnology: The Case for Mediated Posthumanism. Dordrecht/Heidelberg/New York/London: Springer, 3.

[6] Hayles, N. K. (1999). How We Became Posthuman: Virtual Bodies in Cybernetics, Literature, and Informatics. Chicago: University Of Chicago Press, 84.

[7] Wolbring, G. (2006). The unenhanced underclass. Media Development 53 (2): 30-45.

[8] Kass, L. R. (2001). Preventing a brave new world: Why we should ban human cloning now. New republic (New York, N. Y.) 224 (21): 30-39.

[9] Sandberg, A. (2013). "Morphological freedom - Why we not just want it, but need it". In The Transhumanist Reader: Classical and Contemporary Essays on the Science, Technology, and Philosophy of the Human Future. eds. M. More and V. M. Natasha, 56-64. Oxford, United Kingdom: Wiley-Blackwell.

[10] Bailey, R. (2004). Transhumanism: the most dangerous idea? [On-line]. Available: http://reason.com/archives/2004/08/25/transhumanism-the-mo st-dangero (accessed April 2, 2020).

[11] Hughes, J. (2002). Democratic Transhumanism 2.0 [On-line]. Available: http://www.changesurfer.com/Acad/DemocraticTranshumanis m.htm (accessed April 2, 2020).

[12] Whitehead, A. N. (1948). Science and the Modern World. New York: The New American Library, pp. 96-106.

[13] Laszlo, E. (1973). A systems philosophy of human values. Behavioral Science, 18 (4): 250-259.

[14] Taylor, P. 1986. Respect for Nature, Princeton: Princeton University Press, pp. 121-122.

[15] Jiang, J. T. (2019). On the nature of moral from the perspective of systematic axiology. Legal System and Society, (05): $231-232+239$.

[16] Jiang, J. T. (2019). Study on the Marxist view of the essence of value from the perspective of systematic theory of value. The Science Education Article Collects, (04): 44-47.

[17] Jiang, J. T. (2019). A system axiological interpretation and development of scientific socialistic values. New West, (09): 4-6. 